\title{
DFIG Wind Power System with a DDPWM Controlled Matrix Converter
}

\author{
Ji-Heon Lee*, Jong-Kyou Jeong*, Byung-Moon Han ${ }^{\dagger}$, Nam-Sup Choi** and Han-Ju Cha***
}

\begin{abstract}
This paper proposes a new doubly-fed induction generator (DFIG) system using a matrix converter controlled by direct duty ratio pulse-width modulation (DDPWM) scheme. DDPWM is a recently proposed carrier based modulation strategy for matrix converters which employs a triangular carrier and voltage references in a voltage source inverter. By using DDPWM, the matrix converter can directly and effectively generate rotor voltages following the voltage references within the closed control loop. The operation of the proposed DFIG system was verified through computer simulation and experimental works with a hardware simulator of a wind power turbine, which was built using a motor-generator set with vector drive. The simulation and experimental results confirm that a matrix converter with a DDPWM modulation scheme can be effectively applied for a DFIG wind power system.
\end{abstract}

Keywords: Doubly-fed induction generator, Matrix converter, Direct duty ratio pulse-width modulation, Wind power system

\section{Introduction}

A doubly-fed induction generator (DFIG) was developed for a wind power system with a wide variation of wind speed [1], [2]. The stator of the DFIG is directly connected to the power grid while its rotor needs to be connected to the power grid through an ac-ac power converter. The DFIG can supply the constant frequency power to the grid without reference to wind speed variation, and can control the power factor at the connection point [3], [4].

For an ac-ac power converter, indirect topology such as a back-to-back converter has been widely used to connect the rotor output to the power grid and for converting the low frequency ac power into commercial rated frequency power. However, it is well known that back-to-back converters have relatively high loss due to 2-step power conversion such as ac-dc and dc-ac, their bulky structure and maintenance problems due mainly to the dc-link capacitor. In order to overcome these shortcomings, a direct ac-ac power converter, especially a matrix converter, which can directly convert the ac power from one frequency to another, was considered as a power stage by several researchers [4]-[8].

The performance of the matrix converter is strictly dependent upon the employed pulse-width modulation (PWM), which will, in turn, dominantly determine the overall system performance. Because of the complexity of control of a matrix converter, however, its practical implementation would be not easy. This might be one of the

$\dagger \quad$ Corresponding Author: Department of Electrical Engineering Myongji University, Yongin, Korea. (erichan@mju.ac.kr)

* Department of Electrical Engineering Myongji University, Yongin, Korea. (pho1234@mju.ac.kr)

** Division of Electrical Electronic Communication and Computer Engineering, Chonnam National University, Yeasu, Korea. (nschoi@chonnam.ac.kr)

***Department of Electrical Engineering, Chungnam National University. (hjcha@cnu.ac.kr)

Received: January 13, 2010; Accepted: March 9, 2010 main reasons why some previous research concentrated on computer simulations to confirm the feasibility of matrix converter application for a DFIG [4]-[6]. At present, some literature reports the actual implementation and experimental results of a DFIG wind power system with a matrix converter that is controlled by a space vector PWM (SVPWM) [6], [7]. An SVPWM is, however, far from intuitive and requires complicated lookup tables with previously initialized and stored switching patterns [9].

In this paper, a simple and easy modulation scheme for a matrix converter, the so called direct duty ratio PWM (DDPWM), is applied for the DFIG. When using DDPWM, there is no need to obtain a complicated modeling of the matrix converter as in a SVPWM. The DDPWM controlled matrix converter can directly and effectively generate rotor voltages following the voltage references, which employs a triangular carrier and voltage references as in a conventional voltage source inverter. The operation of the proposed DFIG system was verified through both computer simulation and experimental works with a hardware simulator of a wind power turbine built using a motor-generator set.

\section{Control of Matrix Converter}

Fig. 1 shows a circuit configuration including a matrix converter, 3-phase input voltage source, input filter, and DFIG as a load. The matrix converter offers bidirectional power transfer as well as input power factor adjustment. It can directly change the 3-phase ac power to variable voltage variable frequency (VVVF) ac power without a dc link capacitor. The set of bidirectional solid-state switches is the key element in a matrix converter. These switches are gated on or off simultaneously in order to synthesize the desired output voltages. 


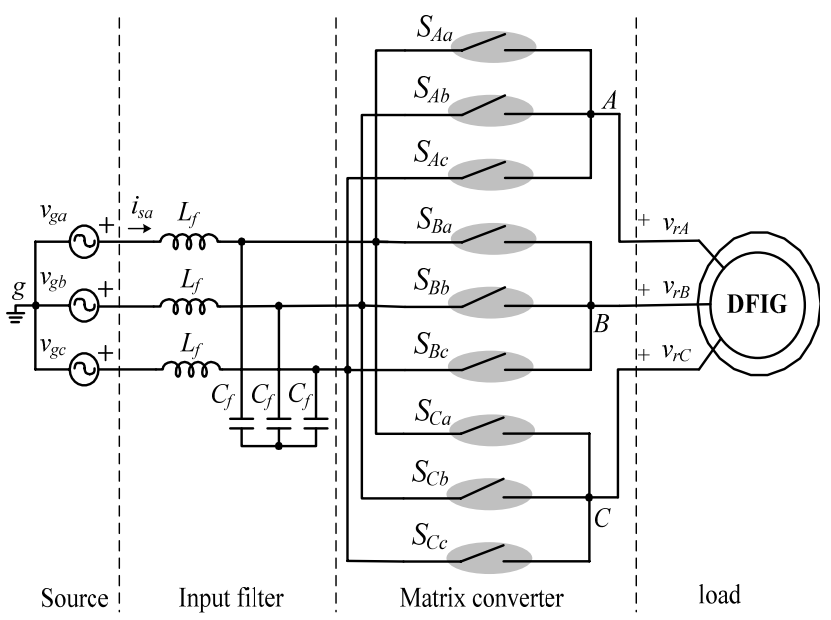

Fig. 1. Configuration of 3-phase matrix converter.

The DDPWM scheme offers an effective way to control a 3-phase matrix converter [10]. For self-completeness, this paper will address the DDPWM as a basic control law to produce the desired three-phase output voltages.

Fig. 2 shows a leg configuration, in particular an Aphase leg, to implement a matrix converter, which can be considered as a basic module to explain the DDPWM because the DDPWM was originally developed using the concept of per-output-phase average over one switching period. In Fig. 2, MX, MD and MN denote the maximum, medium and minimum input phase voltages, respectively as shown in Fig. 3. There are only two cases, either MXMD $>$ MD-MN or MX-MD $<$ MD-MN.

Fig. 4 shows switching pattern-I and pattern-II for generating A-phase output voltage where a triangular carrier is compared with a duty ratio value, $\mathrm{dA}$.

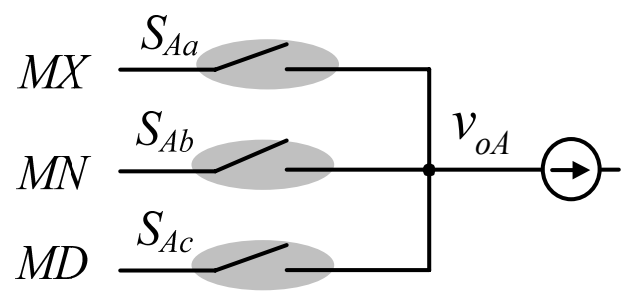

Fig. 2. A leg configuration for a matrix converter.

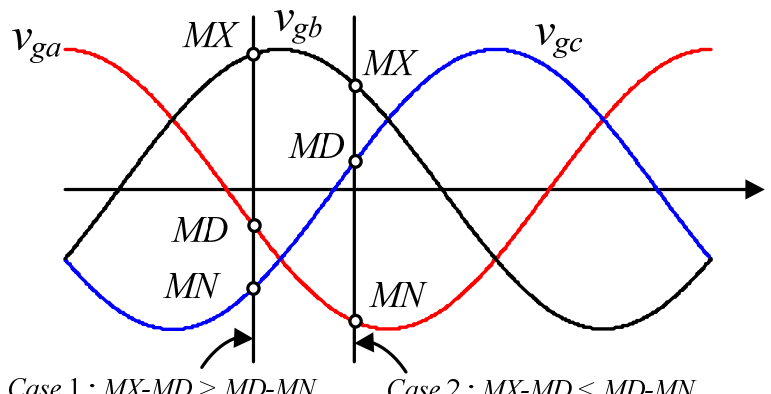

Fig. 3. Two cases for determining switching pattern.
During T1, the line-to-line voltage between MX and MN is used, which is the maximum line-to-line voltage among three line-to-line input voltages at the sampling instant. During T2, the second maximum line-to-line voltage that is the larger one in MX to MD and MD to MN, is used to obtain the output voltage. If MX-MD > MD-MN, MX to MD is used during T2 and the resultant switching pattern is named switching pattern-I. Otherwise, MD to MN is used during T2, and is named switching pattern-II.

The output phase voltage will be changed from $\mathrm{MN} \rightarrow$ $\mathrm{MX} \rightarrow \mathrm{MD}$ for switching pattern-I and $\mathrm{MN} \rightarrow \mathrm{MX} \rightarrow \mathrm{MD} \rightarrow$ $\mathrm{MN}$ for switching pattern-II. The four sub-intervals can be expressed as

$$
\begin{aligned}
T_{A 1} & =d_{A 1} n T_{S} \\
T_{A 2} & =\left(1-d_{A 1}\right) n T_{S} \\
T_{A 3} & =\left(1-d_{A 1}\right)(1-n) T_{S} \\
T_{A 4} & =d_{A 1}(1-n) T_{S}
\end{aligned}
$$

where Ts is the switching frequency and $n$ is defined by $n$ $=\mathrm{T} 1 / \mathrm{Ts}$ which involves the slope of the carrier.

It is found from Fig. 4 that the averaged value of voA, can be approximated by

$$
\begin{aligned}
\bar{v}_{O A} & =\frac{1}{T_{S}} \int_{0}^{T_{S}} v_{O A} d t= \\
& \begin{cases}d_{A}(n \cdot M N-n \cdot M D+M D-M X)+M X & \text { for } \text { pattern-I } \\
d_{A}(M N-n \cdot M X-M D+n \cdot M D)+n \cdot M X-n \cdot M D+M D & \text { for pattern-II }\end{cases}
\end{aligned}
$$

By letting $\bar{v}_{O A}$ be equal to the $A$-phase output voltage command, $v_{O A}^{*}$, that is $\bar{v}_{O A}=v_{O A}^{*}$, the duty ratio value, $d_{A}$, for the present switching period can be calculated as

$$
d_{A}= \begin{cases}\frac{M X-v_{o A}^{*}}{(M X-M D)+n(M D-M N)} & \text { if }(M X-M D) \geq(M D-M N) \\ \frac{n(M X-M D)+\left(M D-v_{o A}^{*}\right)}{n(M X-M D)+(M D-M N)} & \text { if }(M X-M D)<(M D-M N)\end{cases}
$$

The actual gating signals of the bidirectional switches can be directly generated by considering Fig. 2. If the switching state of phase " $A$ " is $M X$ (or $M D, M N$ ), the output phase " $A$ " is connected to the input phase whose voltage is $M X$ (or $M D, M N)$.

It should be noted that, when driving the duty ratio value, $d_{A}$, in Eq. (3), there was no consideration in the other leg's switching state. This means that the multiple output phases can be separately controlled to follow their references. This fact results in the modular structure of the DDPWM. Therefore, it can be concluded that one can easily produce the duty ratio $d_{x},(x=A, B, C)$ for each phase in a 3-phase to 3 -phase matrix converter with 3-leg (see Fig. 1) as given by 


$$
d_{x}= \begin{cases}\frac{M X-v_{o x}^{*}}{(M X-M D)+n(M D-M N)} & \text { if }(M X-M D) \geq(M D-M N) \\ \frac{n(M X-M D)+\left(M D-v_{o x}^{*}\right)}{n(M X-M D)+(M D-M N)} & \text { if }(M X-M D)<(M D-M N)\end{cases}
$$

where $v_{o x}^{*}(x=A, B, C)$ is the reference output voltages at $x$ phase.

The input current can be synthesized by modifying $n$. Meanwhile, output voltage synthesis will not be disturbed since $n$ is already included in (2) and (3). Under the condition of the unit power factor, it can be found that $n$ is determined by

$$
n= \begin{cases}-M N / M X & \text { Switching pattern-I } \\ -M X / M N & \text { Switching pattern-II }\end{cases}
$$

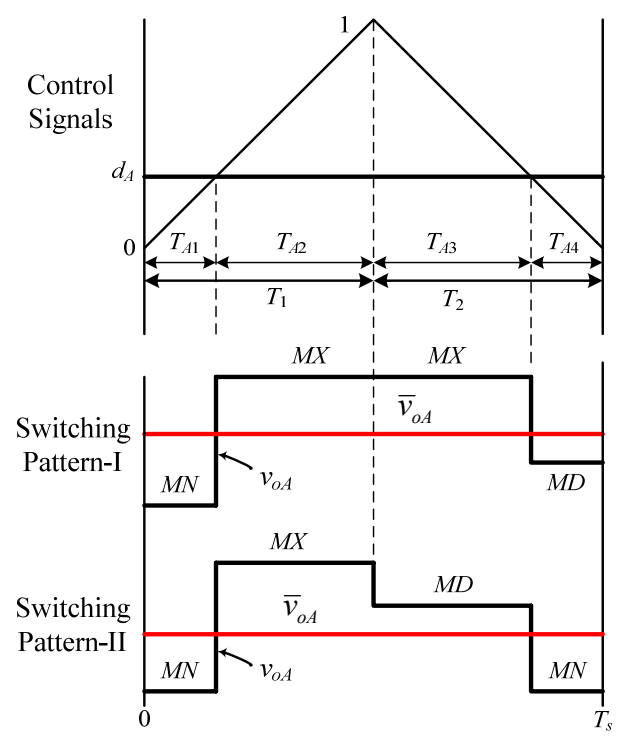

Fig. 4. Output A-phase voltage synthesis.

Fig. 5 shows an example case for generating the whole gating signals when $M X=v_{g a}, M D=v_{g b}, M N=v_{g c}$. In addition, Fig.5(a) illustrates switching pattern-I where $(M X$ $M D)>(M D-M N)$ while Fig. 5(b) switching pattern-II where $(M X-M D)<(M D-M N)$.

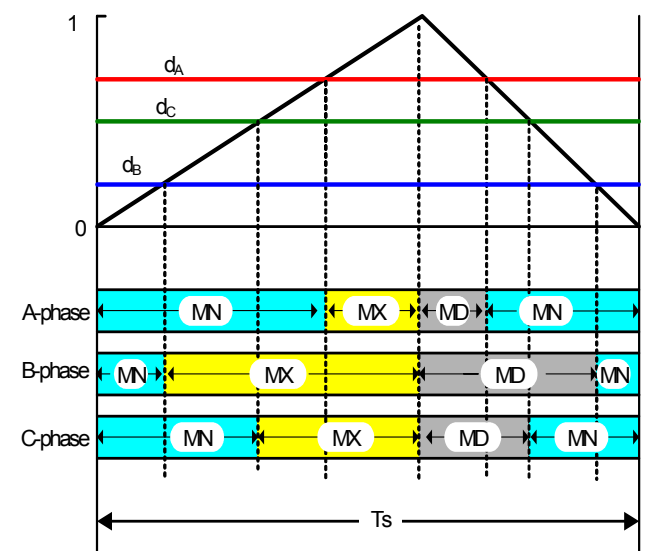

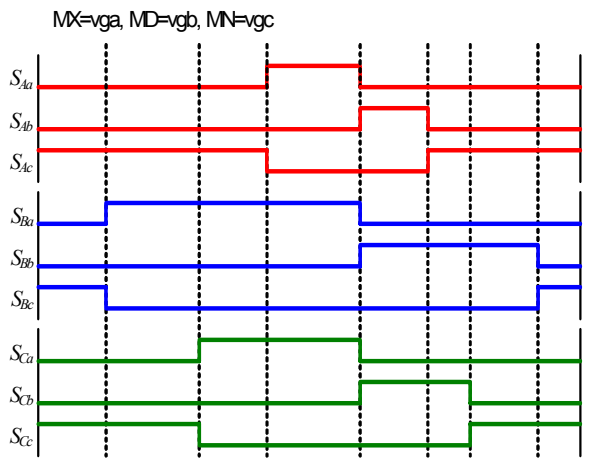

(a)

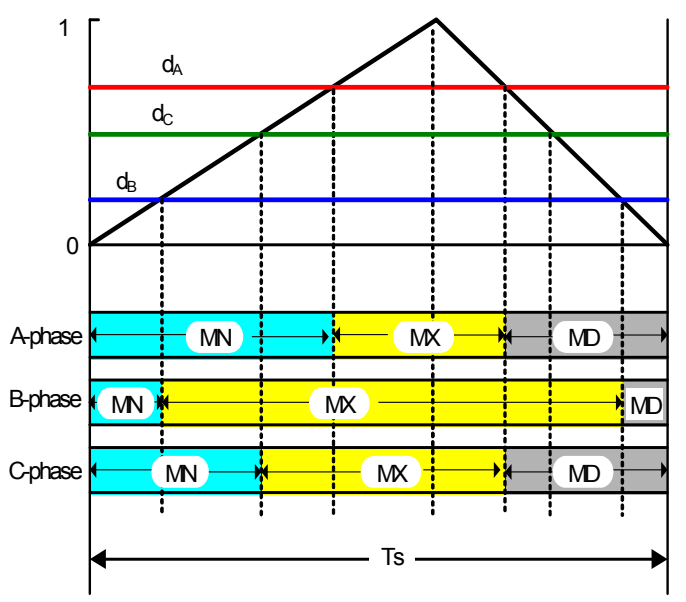

$M X=v g a, M D=v g b, M N=v g c$

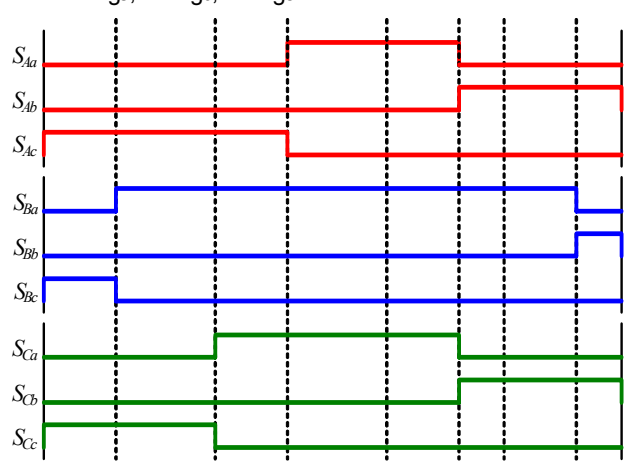

(b)

Fig. 5. Gating signal generation in each case of (a) switching pattern-I (b) switching pattern -II.

\section{Proposed DFIG System}

\subsection{Operational Principle}

Fig. 6 shows a system configuration of the DFIG wind power system with a matrix converter as described in this paper. The stator windings of the DFIG will be connected to the power grid through the circuit breaker when the mechanical power supplied by the blade is large enough. On the other hand, the stator windings will be disconnected to the power grid if the generated mechanical power is not large enough. The rotor windings are connected to the power grid through the matrix converter. Other parts in Fig. 
6 are used for control purposes and will be discussed in detail later.

When the slip is larger than zero or the rotor speed is lower than the synchronous speed, the blade power is only transmitted to the grid through the stator and some part of the blade power is consumed in the rotor. So, the difference between blade power and rotor power is actually transmitted to the grid. On the other hand, when the slip is smaller than zero or the rotor speed is higher than the synchronous speed, the blade power is transferred to the grid through both the stator and the rotor.

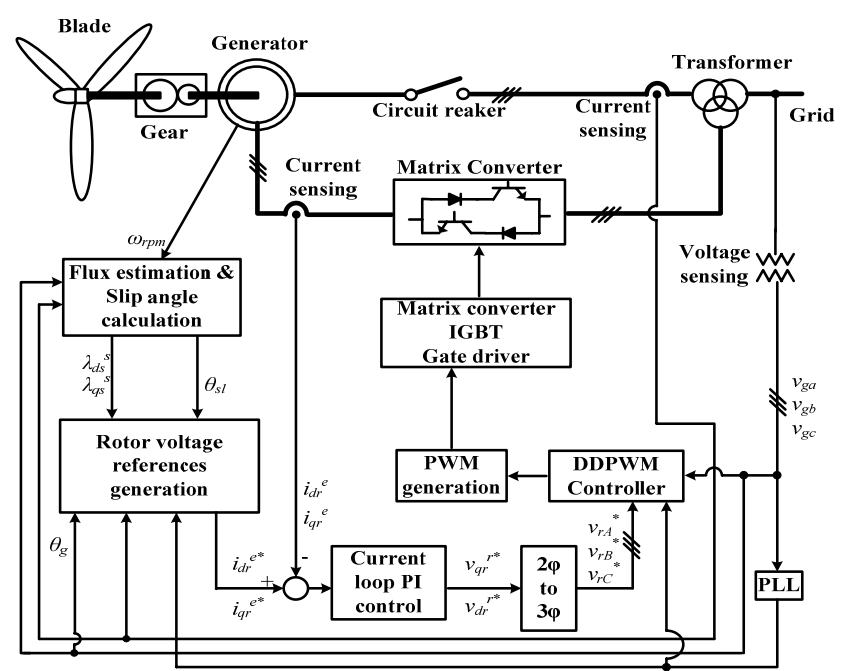

Fig. 6. Proposed DFIG wind power system.

\subsection{System Modeling}

Defining the wind speed to be $V_{\text {wind }}$ and the blade radius to be $R_{\text {blade }}$, the blade power $P_{\text {blade }}$ is described by equation (6).

$$
P_{\text {blade }}=\frac{1}{2} A \rho V^{3}{ }_{\text {wind }} C_{p}
$$

where, $A$ is the rotational area of blade, which is expressed by $\mathrm{A}=\pi R_{\text {blade }}^{2} \rho$ is air density which is about $1.225\left[\mathrm{~kg} / \mathrm{m}^{3}\right]$.

The output power coefficient $C_{p}$ means the ratio of blade energy to wind energy, which is a function of the tip speed ratio $\mu$. The tip speed ratio is defined by the ratio of the blade rotation speed to wind speed.

$$
\mu=\frac{\omega_{\text {blade }} R_{\text {blade }}}{V_{\text {wind }}}
$$

where, $\omega_{\text {blade }}$ is blade angular velocity.

The torque supplied from the blade to the generator, $T_{\text {blade }}$, can be described in Eq. (8).

$$
T_{\text {blade }}=\frac{P_{\text {blade }}}{\omega_{\text {blade }}}
$$

If both stator and rotor windings are in a star connection, the 3-phase dynamic equations for the stator and rotor can be changed as in Eq. (9) using $d-q$ coordinate transform.

$$
\begin{aligned}
& V_{d r}^{g}=r_{r} i_{d r}^{g}+\frac{d}{d t} \lambda_{d r}^{g}-\left(\omega-\omega_{r}\right) \lambda^{g}{ }_{q r} \\
& V^{g}{ }_{q r}=r_{r} i^{g}{ }_{q r}+\frac{d}{d t} \lambda^{g}{ }_{q r}+\left(\omega-\omega_{r}\right) \lambda_{d r}^{g}
\end{aligned}
$$

where, the $\mathrm{q}$ axis is in the direction of $V_{a}$.

In Eq. (9) the superscript $g$ means the reference system. $g$ can be replaced by $S$ for a static reference system and by $e$ for a synchronous reference system. Subscript $d$ and $q$ means $d$ - and $q$ - axis and subscript $s$ and $r$ means stator and rotor, respectively.

$V_{x}, r_{x}, i_{x}, \lambda_{x}$ and $\omega_{r}$ mean voltage, resistance, current, flux and electrical angular velocity, respectively. $\omega$ should be replaced according to the reference system. For the static reference system and for the synchronous reference system, $\omega=\omega_{e}$.

The stator and rotor flux of the induction machine are proportional to the production of impedance and current as shown in Eq. (10).

$$
\begin{aligned}
& \lambda^{g}{ }_{d s}=L_{s} i_{d s}^{g}+L_{m} i^{g}{ }_{d r} \\
& \lambda^{g}{ }_{q s}=L_{s} i^{g}{ }_{q s}+L_{m} i^{g}{ }_{q r} \\
& \lambda^{g}{ }_{d r}=L_{m} i^{g}{ }_{d s}+L_{r} i^{g}{ }_{d r} \\
& \lambda^{g}{ }_{q r}=L_{m} i^{g}{ }_{q s}+L_{r} i^{g}{ }{ }{ }^{2}
\end{aligned}
$$

where, $L_{m}, L_{s}$ and $L_{r}$ are magnetizing inductance, stator inductance and rotor inductance, respectively.

The torque of the induction machine means the mechanical power generated or consumed, which can be expressed by Eq. (11) using stator and rotor currents.

$$
T_{g e n}=\frac{3}{2} \frac{P}{2} \frac{L_{m}}{L_{s}}\left(\lambda^{g}{ }_{q s} i_{d r}^{g}-\lambda_{d s}^{g} i_{q r}^{g}\right)
$$

The active power and reactive power for the stator are defined in Equations (12) and (13).

$$
\begin{aligned}
& P_{\text {stator }}=\frac{3}{2}\left(V_{d s}^{g} i_{d s}^{g}+V_{q s}^{g} i_{q s}^{g}\right) \\
& Q_{\text {stator }}=\frac{3}{2}\left(V^{g}{ }_{q s} i^{g}{ }_{d s}-V^{g}{ }_{d s} i^{g}{ }_{q s}\right)
\end{aligned}
$$

The active power and reactive power for the rotor are defined in Equations (14) and (15) with the same approach.

$$
\begin{aligned}
& P_{\text {rotor }}=\frac{3}{2}\left(V_{d r}^{g} i_{d r}^{g}+V_{q r}^{g} i_{q r}^{g}\right) \\
& Q_{\text {rotor }}=\frac{3}{2}\left(V^{g}{ }_{q r} i^{g}{ }_{d r}-V^{g}{ }_{d r} i^{g}{ }_{q r}\right)
\end{aligned}
$$

The induced stator fluxes determined by (10) can be calculated using the sensed stator currents and the grid voltages. 
These values, $\lambda_{d s}{ }^{s}$ and $\lambda_{q s}{ }^{s}$, are then transferred to $\lambda_{d s}{ }^{e}$ and $\lambda_{q s}{ }^{e}$ in a synchronous reference system.

Fig. 7 shows a detailed configuration of the system controller for the proposed DFIG system. It is assumed that the grid side is assigned to the input side of the matrix converter and the rotor side is assigned to the output side.

The maximum power can be extracted when the $\mu$ has a maximum value. So, the reference rotor speed $\omega^{*}{ }_{r p m}$ at the maximum power point is expressed in Eq. (16). The actual rotor speed $\omega_{r p m}$ is measured with an encoder and compared with the $\omega^{*}{ }_{r p m}$. The error is passed through the PI control to generate the $q$ axis current reference $i_{q r}{ }^{*}$.

$$
\begin{array}{r}
\omega_{r p m}^{*}=\frac{\mu V_{\text {wind }}}{R_{\text {blade }}} \\
i_{q r}^{*}=\left(\omega_{r p m}^{*}-\omega_{r p m}\right)\left(K_{p}+\frac{K_{I}}{S}\right)
\end{array}
$$

The $d$ axis current reference $i_{d r}{ }^{e^{*}}$ can be obtained by comparing $Q_{\text {stator }}{ }^{*}$ and $Q_{\text {stator }}$ from the feed forward calculation. Then $i_{q r}{ }^{e^{*}}$ and $i_{d r}{ }^{e^{*}}$ are compared with $i_{q r}{ }^{e}$ and $i_{d r}{ }^{e}$ respectively to generate the error signals. These error signals will be processed by a PI controller. $V_{q r}{ }^{e^{*}}$ and $V_{d r}{ }^{e^{*}}$ will be processed by $d-q$ inverse transform to generate the reference 3-phase voltage $v_{r A}{ }^{*}, v_{r B}{ }^{*}$ and $v_{r C}{ }^{*}$. These reference voltages are sent to the DDPWM controller to generate the gate signals for the matrix converter.

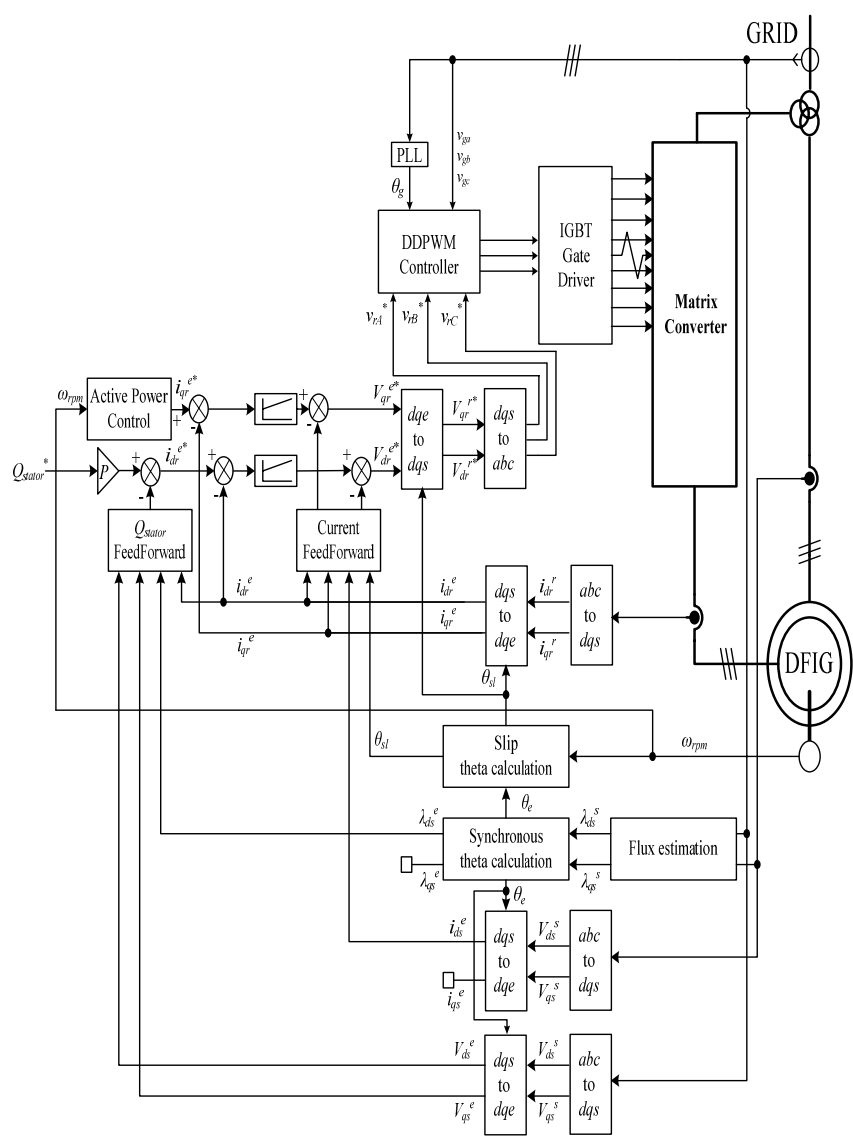

Fig. 7. Controller for the proposed DFIG wind power system.

\section{Simulation}

Many computer simulations with PSCAD/EMTDC software were carried out to confirm the operation of the DFIG and matrix converter with the proposed modulation scheme. The DFIG wind power system is represented by a wind turbine model and wound-rotor induction generator, of which the rotor is connected to the power grid through the matrix converter operating with the proposed modulation scheme. The controller is represented by a user-defined model with $\mathrm{C}$ language. Table 1 contains the major parameters used in simulations.

Table 1. Parameters for simulation model

\begin{tabular}{c|c}
\hline Grid voltage (L-L rms value) & $220 \mathrm{~V}$ \\
\hline Line frequency & $60 \mathrm{~Hz}$ \\
\hline Nominal wind speed & $12 \mathrm{~m} / \mathrm{s}$ \\
\hline Blade length & $1.78 \mathrm{~m}$ \\
\hline Generator specification & $220 \mathrm{~V}, 3.7 \mathrm{~kW}$ \\
\hline Rotor coupling transformer & $110: 220(\triangle-\mathrm{Y})$ \\
\hline Switching frequency & $5 \mathrm{kHz}$ \\
\hline Number of poles & 6 \\
\hline$C_{p}(\max )$ & 0.323 \\
\hline
\end{tabular}

Fig. 8 shows the simulation results. Fig. 8(a) shows the variation of wind speed, which increases up to $11 \mathrm{~m} / \mathrm{s}$ from $40 \mathrm{sec}$ to $50 \mathrm{sec}$ and up to $13 \mathrm{~m} / \mathrm{s}$ from $50 \mathrm{sec}$ to $60 \mathrm{sec}$. The rotating speed of the rotor, the active powers from the rotor and stator, active power sent to the grid are shown in curves, 8(b), 8(c), 8(d), and 8(e), respectively.

It can be shown that the stator power $P_{\text {stator }}$ is always greater than zero, which means the generated active power flows from the stator to the grid. However, whether the rotor receives or sends the active power to the grid will depend on slip. When the rotor speed is lower than the synchronous speed, the stator supplies power to the grid and the rotor absorbs power from the grid. The difference between the stator power and rotor power is supplied to the grid. As shown in the graphs, the rotor power $P_{\text {rotor }}$ is smaller than zero while the rotor speed $\omega_{r p m}$ is below the synchronous speed. On the contrary, the rotor power $P_{\text {rotor }}$ will be positive while the rotor speed $\omega_{r p m}$ is greater than the synchronous speed. Finally, it can be verified that the total power sent to the grid will always be positive.

Fig. 9 shows the simulation results of rotor current, stator voltage, and rotor power with respect to the rotor speed $\omega_{\text {rpm }}$. In Fig. 9(a), the frequency of rotor current at $\omega_{r p m}=900 \mathrm{rpm}$ is about $15 \mathrm{~Hz}$. The magnitude of rotor current will be determined by generator torque. It is clear that the rotor consumes about $400 \mathrm{~W}$ of active power from the grid at $\omega_{r p m}=900 \mathrm{rpm}$. In Fig. 9(b), the frequency of rotor current at $\omega_{r p m}=1200 \mathrm{rpm}$ is almost zero because the slip is zero. Resultantly, the rotor current implies dc value. However, the active power is below zero because of generator loss. In Fig. 9(c), the frequency of rotor current at $\omega_{r p m}=1400 \mathrm{rpm}$, is about $10 \mathrm{~Hz}$. The rotor supplies active power to the grid. 


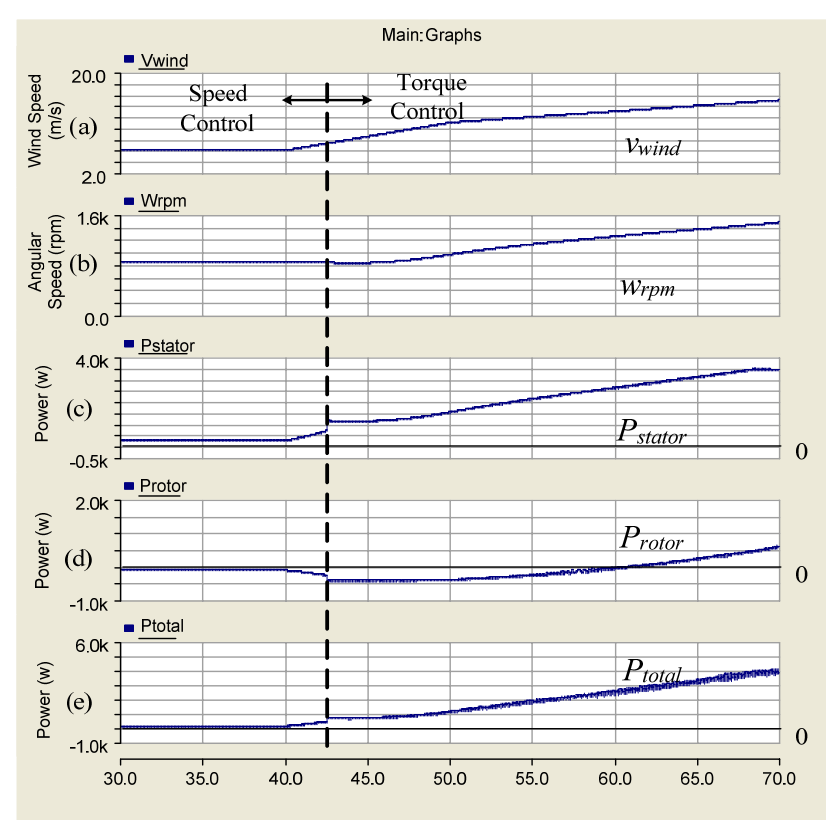

Fig. 8. Generated power with respect to wind speed.

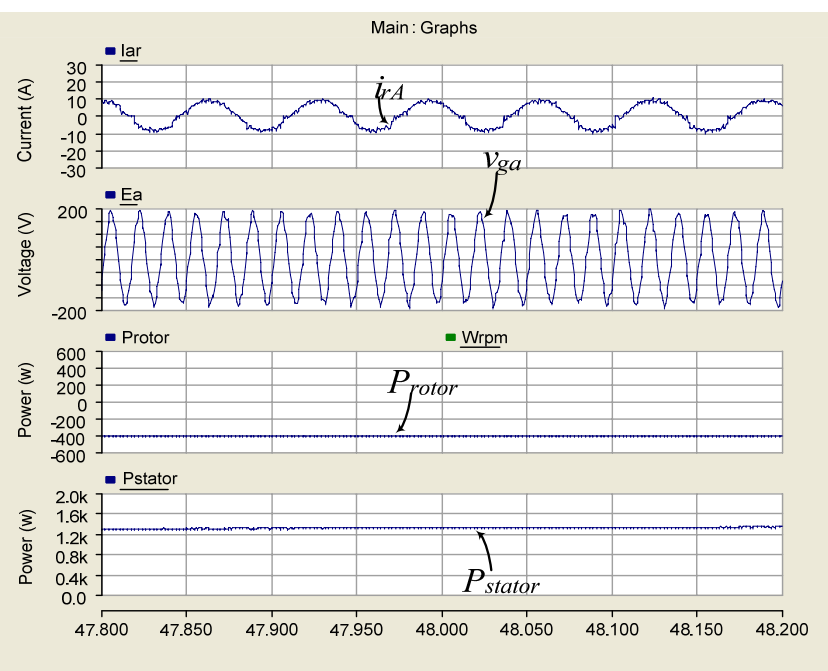

(a) $\omega_{r p m}=900 \mathrm{rpm}$

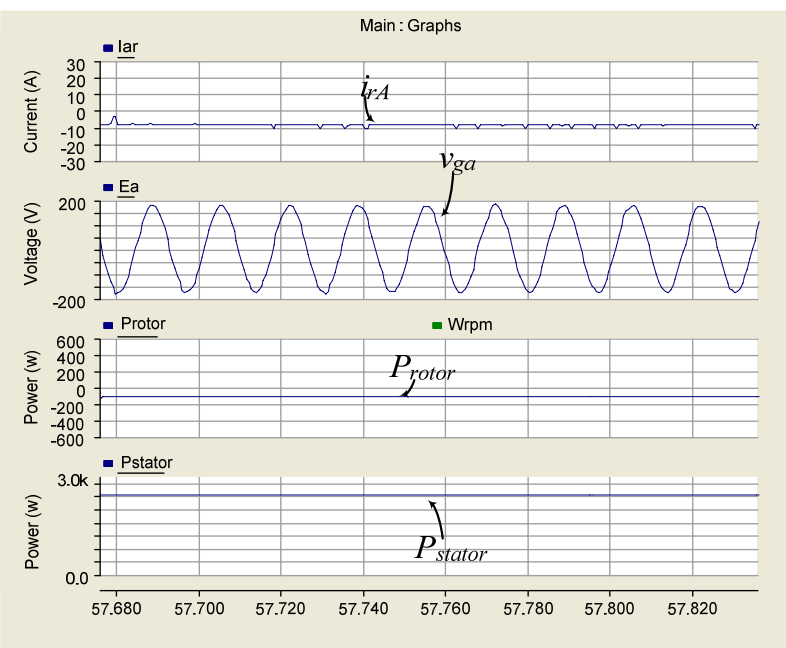

(b) $\omega_{r p m}=1200 \mathrm{rpm}$

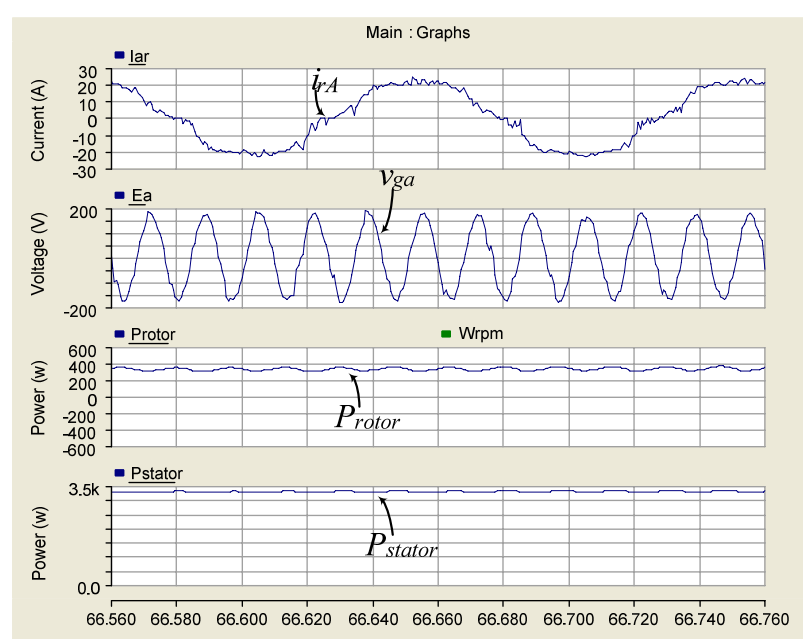

(c) $\omega_{\text {rpm }}=1400 \mathrm{rpm}$

Fig. 9. Simulation results with respect to $\omega$ rpm.

\section{Experiment}

A hardware simulator for the wind power system was built using a squirrel-cage induction motor with a vector drive and a wound-rotor induction generator with a matrix converter. The mechanical characteristic of the wind turbine is simulated using a squirrel-cage induction motor with a vector drive. The DFIG wind power system is simulated using a wound-rotor induction generator and matrix converter with the proposed modulation scheme. Fig. 10 shows a picture of the wind power simulator built in the lab. The squirrel-cage induction motor with a vector drive and the wound-rotor induction generator are built in a test bed. The matrix converter and DSP controller are built in a separate panel. The controller for the matrix converter is built with a 32bit Floating-Point DSP, the TMS320VC33.

Table 2 shows the major circuit parameters of the hardware simulator used in the experimental works. A transformer rated $110 / 220 \mathrm{~V}$ is connected between the input side of the matrix converter and the grid for voltage matching.

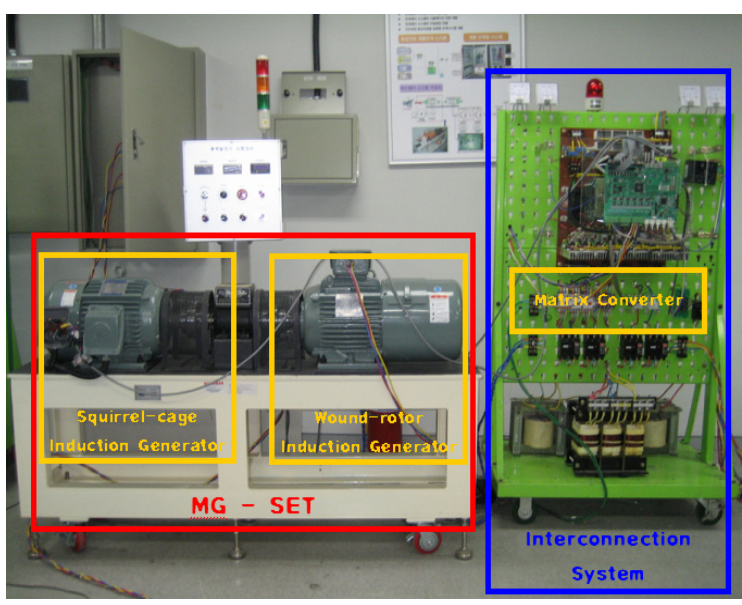

Fig. 10. Hardware scaled-model. 
Table 2. Circuit parameters of hardware simulator

\begin{tabular}{c|c}
\hline Bus voltage $(\mathrm{rms} \mathrm{L}-\mathrm{L})$ & $220 \mathrm{~V}$ \\
\hline Frequency & $60 \mathrm{~Hz}$ \\
\hline Motor rating & $7.5 \mathrm{~kW}$ \\
\hline Motor nominal speed & $1750 \mathrm{rpm}$ \\
\hline Generator rating & $3.7 \mathrm{~kW}$ \\
\hline Switching frequency & $5000 \mathrm{~Hz}$ \\
\hline Transformer & $110: 220(\triangle-\mathrm{Y})$ \\
\hline Number of poles & 6 \\
\hline
\end{tabular}

Fig. 11 shows the experimental results using the scaled hardware simulator. The stator power, rotor power, rotor current, and stator voltage were measured in the cases of the rotor speed of $900 \mathrm{rpm}, 1200 \mathrm{rpm}$, and $1400 \mathrm{rpm}$, respectively.

Fig. 11(a) shows that when the rotor speed is $900 \mathrm{rpm}$, the stator supplies active power to the grid and the rotor consumes the active power. But the total power obtained from the blade to the grid is positive. The stator voltage is maintained the same as the grid voltage and the rotor current is of low frequency ac waveform proportional to the slip.

Fig. 11(b) shows that when the rotor speed is $1200 \mathrm{rpm}$, the stator sends power to the grid and the rotor active power is not exactly zero, but a small negative value, which is due to the generator loss and converter switching loss. However, the total power received from the blade to the grid is positive. The stator voltage is maintained the same as the grid voltage, and the rotor current shows dc value because the slip is zero.

Fig. 11(c) shows that when the rotor speed is $1400 \mathrm{rpm}$, both the stator and rotor send active power to gird. The stator voltage is maintained the same as the grid voltage and the rotor current shows low frequency $\mathrm{AC}$ waveform proportional to the slip.

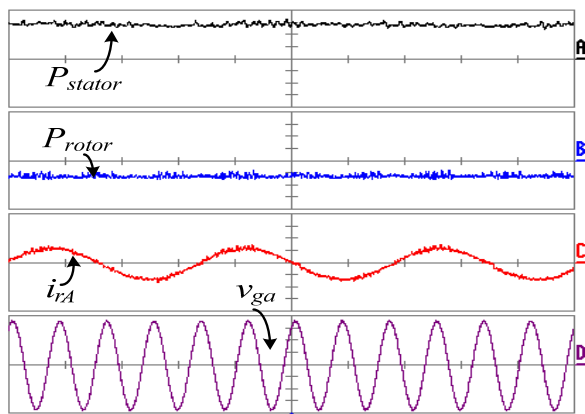

(a) $\omega_{\text {rpm }}=900 \mathrm{rpm}\left(20 \mathrm{~ms} / \mathrm{div}, P_{\text {stator }}: 400 \mathrm{~W} / \mathrm{div}\right.$, $\left.P_{\text {rotor }}: 400 \mathrm{~W} / \mathrm{div}, i_{r A}: 8 \mathrm{~A} / \mathrm{div}, v_{g a}: 50 \mathrm{~V} / \mathrm{div}\right)$

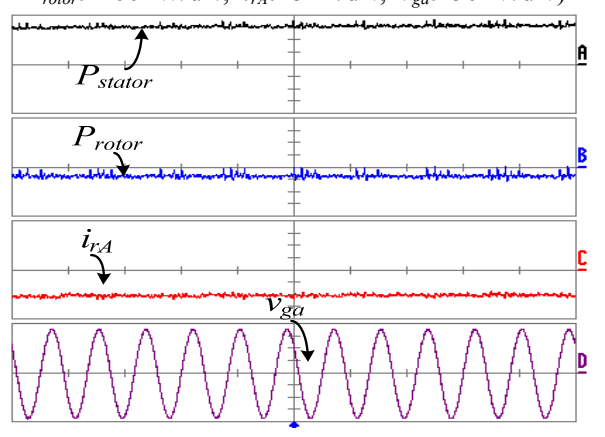

(b) $\omega_{r p m}=1200 \mathrm{rpm}\left(20 \mathrm{~ms} / \mathrm{div}, P_{\text {stator }}: 800 \mathrm{~W} / \mathrm{div}\right.$, $\left.P_{\text {rotor }}: 400 \mathrm{~W} / \mathrm{div}, i_{r A}: 8 \mathrm{~A} / \mathrm{div}, v_{g a}: 50 \mathrm{~V} / \mathrm{div}\right)$

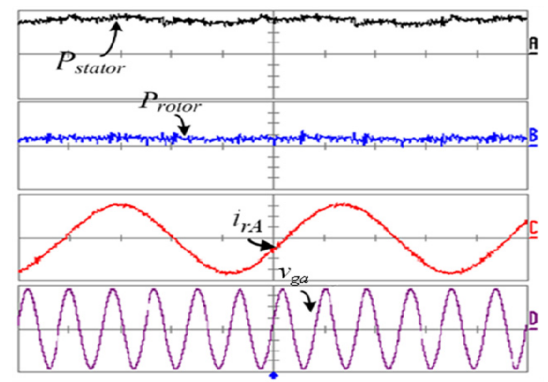

(c) $\omega_{r p m}=1400 \mathrm{rpm}\left(20 \mathrm{~ms} / \mathrm{div}, P_{\text {stator }}: 1100 \mathrm{~W} / \mathrm{div}\right.$ $\left.P_{\text {rotor }}: 400 \mathrm{~W} / \mathrm{div}, i_{r A}: 8 \mathrm{~A} / \mathrm{div}, v_{g a}: 50 \mathrm{~V} / \mathrm{div}\right)$

Fig. 11. Experimental results of hardware scaled-model.

\section{Conclusion}

In this paper, a simple and effective modulation scheme for a matrix converter, a so called DDPWM, is applied for the DFIG wind power system. Compared to the SVPWM widely used in matrix converters, a DDPWM does not require a complicated modeling of the matrix converter, which means that there is no need to previously initialize complicated lookup tables and store switching patterns with a large amount of memory. The DDPWM controlled matrix converter can directly and effectively generate the rotor voltages following the voltage references, which employs a triangular carrier and such voltage references. The operation of the proposed DFIG wind power system was verified through computer simulations with PSCAD/EMTDC software. The feasibility of hardware implementation was confirmed by experimental works with a hardware simulator of a DFIG wind power system with real wind data. The simulation and experimental results confirm that the matrix converter with the proposed modulation scheme can be effectively applied for the DFIG wind power system.

\section{Acknowledgements}

This work was financially supported by the advanced human resource development program of MKE through the Research Center in Myongji University and the 2nd Brain Korea 21 Project.

\section{References}

[1] Dr. Eggaert and S. Franko, "Innovative Variable Speed Drive for Doubly Fed Wind Turbine Application," 2002 Global Wind Power Conference, July 2002.

[2] Chad Abbey and Geza Joos, "Optimal Reactive Power Allocation in a Wind Powered Doubly-Fed Induction Generator," 2004 IEEE Power Engineering General Meeting, pp. 1492-1496, June 2004.

[3] Rajib Datta and V. T. Ranganathan, "A Method of Tracking the Peak Power Points for a Variable Speed 
Wind Energy Conversion System," IEEE Transactions on Energy Conversion, Vol. 18. No. 1, pp. 163-168, March 2003.

[4] L. Zhang and C. Watthanasarn, "A Matrix Converter Excited Doubly-Fed Induction Machine as A Wind Power Generator," IEE 7th International Conference on Power Electronics and Variable Speed Drives, pp. 532-537, London, Sept. 1998.

[5] K. Ghedamsi, D. Aouzellag and E. Berkouk, "Application of Matrix Converter for Variable Speed Wind Turbine Driving a Doubly-Fed Induction Generator," International Symposium on Power Electronics, Electrical Drives, Automation and Motion, SPEEDAM 2006, pp. 38-42, 2006.

[6] S. Pinto, L. Aparicio and P. Esteves, "Direct Controlled Matrix Converters in Variable Speed Wind Energy Generation Systems," International Conference on Power Engineering 2007, Setubal, Portugal, pp. 654-659, April 12-14, 2007.

[7] Lie Xu, Dawei Zhi and Barry W. Williams, "Predictive Current Control of Doubly Fed Induction Generators," IEEE Transactions on Industrial Electronics, Vol. 56. No.10, pp. 4143-4153, October 2009.

[8] Roberto Cárdenas, Rubén Peña, Germán Tobar, Jon Clare, Patrick Wheeler and Greg Asher, "Stability Analysis of a Wind Energy Conversion System based on a Doubly Fed Induction Generator fed by a Matrix Converter," IEEE Transactions on Industrial Electronics, Vol. 56. No. 10, pp. 4194-4206, October 2009.

[9] P. W. Wheeler, J. Rodriguez, J. C. Clare, L. Empringham and A. Weinstein, "Matrix converters: a technology review," Industrial Electronics, IEEE Transactions on, Vol. 49, No. 2, pp. 276-288, 2002.

[10] Yulong Li, Nam-Sup Choi, Byung-Moon Han, KyungMin Kim, Buhm Lee and Jun-Hyub Park, "Direct duty ratio pulse width modulation method for matrix converters," International Journal of Control, Automation, and Systems, Vol. 6, No. 5, pp. 660-669, October, 2008.

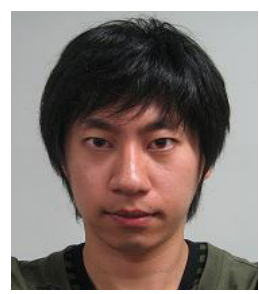

Ji-Heon Lee received his B. S. and Master degrees in Electrical Engineering from Myongji University, Korea, in 2008 and 2010 respectively. He is currently a $\mathrm{Ph}$. D. candidate at Myongji University. His research interests are in power electronics applications for custom power and distributed generation.

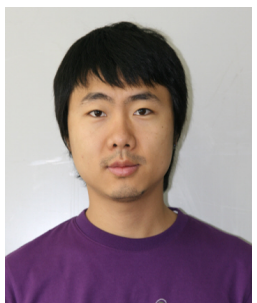

Jong-Kyou Jeong received his B. S. and Master degrees in Electrical Engineering from Myongji University, Korea, in 2008 and 2010 respectively. $\mathrm{He}$ is currently a Ph. D. candidate at Myongji University. His research interests are in power electronics applications for custom power and distributed

generation.

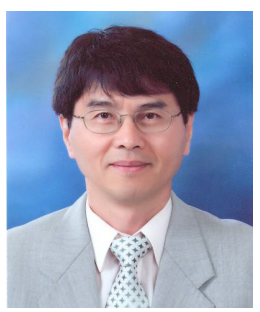

Byung-Moon Han (S'91-M'92-SM'00) received his B.S. in Electrical Engineering from Seoul National University, Korea, in 1976, and his M.S. and Ph.D. from Arizona State University in 1988 and 1992, respectively. He was with the Westinghouse Electric Corporation as a Senior Research Engineer in the Science and Technology Center. Currently, he is a Professor in the Department of Electrical Engineering at Myongji University, Korea. His research interests are in power electronics applications for FACTS, custom power, and distributed generation.

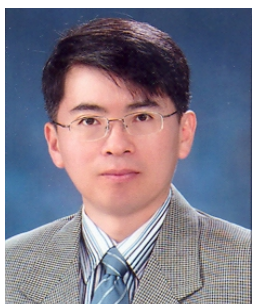

Nam-Sup Choi received his B.S. degree in Electrical Engineering from Korea University in 1987. He received his M.S. degree and D.S. degree in Electrical Engineering at the Korean Advanced Institute of Science and Technology (KAIST) in South Korea in 1989 and 1994, respectively. He is currently a professor in the Department of Electrical Engineering, Chonnam National University, South Korea. His research interests include Modeling and control of power converters and systems.

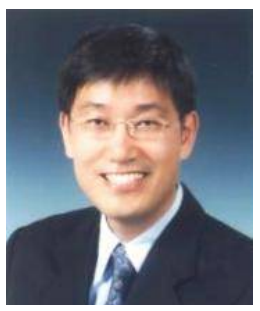

Hanju Cha received his B.S. degree in electrical engineering form Seoul National University, Seoul, Korea, his M.S. degree from Pohang Institude of Science and Technology, Korea, and his Ph.D. degree from Texas A\&M University, College Station, in 1988, 1990 and 2004, respectively, all in electrical engineering. From 1990 to 2001, he was with LG Industrial Systems, Anyang, Korea, where he was engaged in the development of power electronics and adjustable speed drives.

In 2005, he joined the Department of Electrical Engineering, Chungnam National University, Daejeon, Korea. His current research interests are high-power converters, ac/dc, $\mathrm{dc} / \mathrm{ac}$ and ac/ac converter topologies, power quality, and utility interface issues for distributed energy systems and microgrids. 